\title{
Abbreviations
}

\begin{tabular}{|c|c|}
\hline $\mathrm{ABF}$ & betarnas bildningsförbund (Workers' Educational Association) \\
\hline FPF & Fackliga propagandaförbundet (Trade Union Propaganda League) \\
\hline DGT & International Organization of Good Templars \\
\hline KF & Kooperativa förbundet (Cooperative Union) \\
\hline KUF & Kommunistiska Ungdomsförbundet (Communist Youth League) \\
\hline LO & Landsorganisationen (Trade Union Confederation) \\
\hline $\mathrm{NOV}$ & $\begin{array}{l}\text { Nykterhetsorganisationen Verdandi (Temperance Organization } \\
\text { Verdandi) }\end{array}$ \\
\hline SAC & $\begin{array}{l}\text { Sveriges arbetares centralorganisation (Central Organization of the } \\
\text { Workers of Sweden) }\end{array}$ \\
\hline SAF & Svenska arbetsgivareföreningen (Swedish Employers' Association) \\
\hline SAP & Socialdemokratiska arbetarpartiet (Social Democratic Party) \\
\hline SDU & $\begin{array}{l}\text { Socialdemokratiska ungdomsförbundet (Social Democratic Youth } \\
\text { Organization, 1903-17) }\end{array}$ \\
\hline SDUK & $\begin{array}{l}\text { Socialdemokratiska ungdomsklubben (Social Democratic Youth } \\
\text { Club) This was the most common name of the local associations of } \\
\text { SDU. After the party split in 1917, some of the local youth associations } \\
\text { kept their original name even though the correct name after } 1917 \text { is } \\
\text { SSU. }\end{array}$ \\
\hline SKP & $\begin{array}{l}\text { Sveriges kommunistiska parti (Communist Party of Sweden, } \\
\text { 1921-1967) }\end{array}$ \\
\hline SSU & $\begin{array}{l}\text { Sveriges socialdemokratiska ungdomsförbund (Swedish Social Dem- } \\
\text { ocratic Youth League, 1917-) }\end{array}$ \\
\hline SSV & $\begin{array}{l}\text { Socialdemokratiska vänsterpartiet (Social Democratic Left Party, } \\
\text { 1917-1921, referred to as the Left Party) }\end{array}$ \\
\hline SUF & $\begin{array}{l}\text { Socialistiska ungdomsförbundet (Socialist Youth League, also known } \\
\text { as the Young Socialists) }\end{array}$ \\
\hline P & Sveriges ungsocialistiska parti (Swedish Young Socialist Party) \\
\hline
\end{tabular}





\section{CRAFTING THE MOVEMENT}


